\title{
Turbulent Flow Numerical Simulation for Unconventional Propulsion
}

\author{
IONUT CRISTIAN SCURTU ${ }^{*}$, VALERIU NICOLAE PANAITESCU \\ 'Mircea cel Batran Naval Academy, 1 Fulgerului Str., 900218, Constanta, Romania \\ 2University Politehnica of Bucuresti, 313 Splaiul Independentei, 060042, Buchaest, Romania
}

\begin{abstract}
This paper presents mainly a new HPC/CFD numerical simulation for airflow around the rigid sail for Lupo90 boat in Constanta harbor conditions. The first part of the work displays the performed numerical simulation in turbulent flow based on the 3D sail. The presented model has high capacity of towing and it can be installed onboard existing ships. This is the result of the HPC (high performance computing) and CFD (computational fluid dynamics) which is a mixture of actual hardware and software at high level computing power applied to Lupogo boat. All data for rigid sail is analyzed in a turbulent flow in commercial fluid dynamics ANSYS module CFX available at Naval Academy and the work was supported by Romanian Ministry of Defense. Sail performance studying in turbulent flow for the rigid sail onboard ships was always a huge computational difficulty and the HPC/CFD analysis available can solve tricky tasks. The most common unconventional systems are hybrid propulsion systems are using fossil fuel and wind energy, this type of HPC/CFD method for propulsion investigation is now implemented by craft constructor CirusPlast $S R L$.
\end{abstract}

Keywords: numerical simulation, turbulent airflow, sail propulsion.

Conventional fuels will continue to dominate the energy market and petroleum fuels are most used in the transportation sector. Worldwide consumption of petroleum fuels has a continuous dynamics, and the situation on regions is different. Estimates for 2020 according to which the global product portfolio will grow from 23 million barrels per day to 105 million barrels per day.

In this context, pollution from combustion emissions has increased in the last decades and for pleasure crafts, we now focus on sails and other systems with substantial fuel savings. For this reason, the shipping industry is vigorously looking at ways to reduce fossil fuel consumption and operate in a more environmentally friendly way. Referring to the concepts of green shipping, green logistics and sustainable shipping, these are now important issues for ship owners, shipping lines and ship builders globally. Furthermore, numerous regulations and initiatives are being implemented being aimed at reducing emissions from ship. A good example of a ship built with the aim of reducing fuel consumption is the ship with sails [1]. Going back in the 1980's, several J apanese ships were fitted with rigid sails due to the oil crisis [2,3] in the 1970's which resulted in oil shortages and the price of oil rising [4].

The overall goal of this study is to perform a simulation for sail used on board of the crafts and small ships.

The flow around the sail is solved in simulation using finite volume method for airflow domain. Design Modeller numerical program is used to create the 3D geometry for flow simulation around the sail and geometry is imported in CFX solver for drag and lateral force analysis performed with CFD (Computational Fluid Dynamics). [5] A numerical program is employed to calculate the total aerodynamic force acting upon the sail and to study the flow characteristics. All of the forces (drag and side force) from variable curvature rigid sails were emphasized as each of them has a certain part in craft manoeuvring. The simulation, performed with CFD (Computational Fluid Dynamics), was made for different working conditions by varying the incidence angle and the angle of attack for variable curvature rigid sails. The volume of fluid was meshed into an unstructured mesh using two methods of mesh each with its advantages and disadvantages. The boundary layer around the sail presented a special mesh. The pressure and speeds are presented in CFD-Post and forces variation is presented for craft operation.

Computational Fluid Dynamics (CFD) is used for design optimization in ship construction; in this case we performed $3 D$ variable curvature rigid sails profile simulation with CFX. In the context of using sails on board of the crafts, we can use CFD methods to determine parameters of propulsion.

Based on the optimization results, designers can choose a better solution for challenges in mount and analyse sails for ships that were not initially fitted with sails. The numeric modelling of any process was demonstrated to be a valuable tool in the design of engineer hands.

The LUPO 90 can be used both for recreation and for fishing (figure 1). Areas where the boat can navigate are: inland waters, the Danube and the lakes and the sea. The boat was built by SC CIRUS PLAST SRL Constanta in accordance with harmonized European standards. [6] The boat is made of PAFS (fiberglass reinforced polyester). The boat has open cockpit, double bottom and a central cabin and the following dimensions: length: $8.56 \mathrm{~m}$, beam: 2.60 $\mathrm{m}$, draft: $0.5 \mathrm{~m}$, loading: $3000 \mathrm{Kg}$, engine: $90 \mathrm{CP}$ and boat weight: $1500 \mathrm{Kg}$.

For simulated results of the flow around the rigid sail, we will use the geometry modelled in figure 2. ANSYS-CFX is used as a numerical program for a scaled experiment instead of using a costly full-scale experiment $[7,8]$. The flow simulation for the sail uses Reynolds up to $6.25 \times 10^{6}$

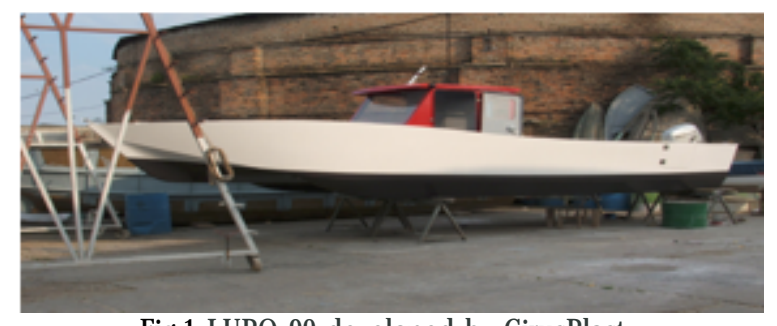

Fig.1 LUPO 90 developed by CirusPlast 
and it will ask for computing hardware performance for best results $[9,10]$.

Defining the physics of the sail model is different from the analytical model of the drag and the side force, presented in as:

$$
\begin{aligned}
& D=\frac{\rho}{2} C_{x} A v^{2}, \\
& S=\frac{\rho}{2} C_{y} A v^{2},
\end{aligned}
$$

where:

$D=$ drag force, acting in the direction of airflow ( $x$ axisfrom stern to bow);

$S=$ side force, perpendicular to the direction of airflow (y axis);

$V=$ velocity of airflow in simulation;

$C_{x^{\prime}} C_{y}=$ coefficients depending on the shape profile and the angle of inclination $\varphi$ of the surface $A$;

$\rho=$ air density (at normal atmospheric pressure and temperature $15^{\circ} \mathrm{C}$ ).

Different positions of the sail in the air, as defined by the angles $\varphi$ and $\theta$ represent the simulation region of interest. The paper will present all results using the same mathematical turbulent modelling the Solver component that solves the CFD problem and produces the required results in a non-interactive user process using time steps and residuals.

\section{Numerical simulation}

Because the wind's direction is different from the ship's direction, then the sail's position in the air may definitely change. The CFX flow solver will calculate results in CFXPost that contains the variation of velocity, pressure and any other variables needed inside the defined the region of interest.

The fluid flow results can be visualized in CFX-Post and will provide the engineer requested simulation data.

The sail characteristics are:

-length of sail $15.0 \mathrm{~m}$;

-sail span $\quad 3 \mathrm{~m}$;

-sail area $\quad 45 \mathrm{~m}^{2}$;

-surface smooth;

$-\varphi$ varies related to horizontal plane along $x$ axis: $0^{0}, 5^{0}$, $10^{\circ}, 15^{\circ}, 20^{\circ}$; $10^{\circ}$.

$-\theta$ varies related to vertical plane along y axis: $0^{0}, 2^{0}, 5^{0}$,

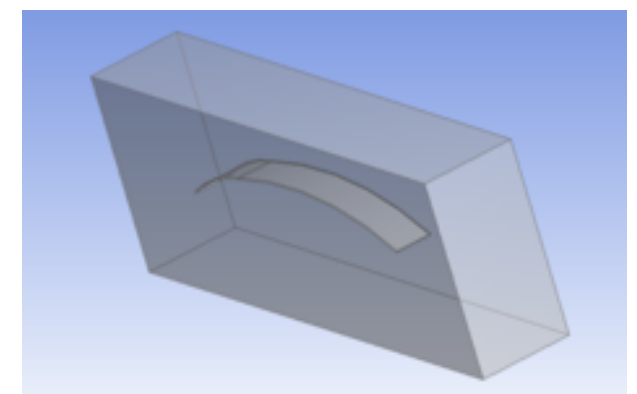

Fig. 2 Variable curvature rigid 3D sail geometry

\section{Sail simulation model settings and mesh}

Design Modeler geometric shape representing the sail is used as tool body in the Boolean operation of subtractive from the fluid domain. CFD can be used to determine the performance of a component at the projectstage and steps like mesh are important for clear results.

ANSYS CFX simulation steps are: geometry, mesh, CFXpre and CFX-Post all are required to perform a complete CFD simulation.

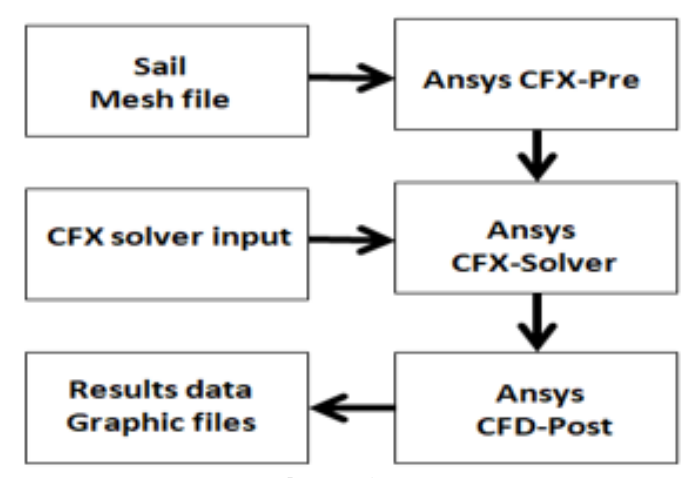

Fig. 3 Schema for CFX steps

The sail's simulation will use CFX inside the Workbench (figure 3 ) in order to edit the geometry and mesh if requested by simulation parameters. The decision of making the process has a great influence in choosing the ship's equipment like variable curvature rigid sails, the goal being to selectan optimal choice in a given context, which can be achieved with high precision simulation results with CFX in Workbench components [12, 13]. The HPC/CFD analysis should be carried out for each type of ship to ensure maximum efficiency using a software code for CFD and a high power computing hardware to solve more than $3,000,000$ cells.

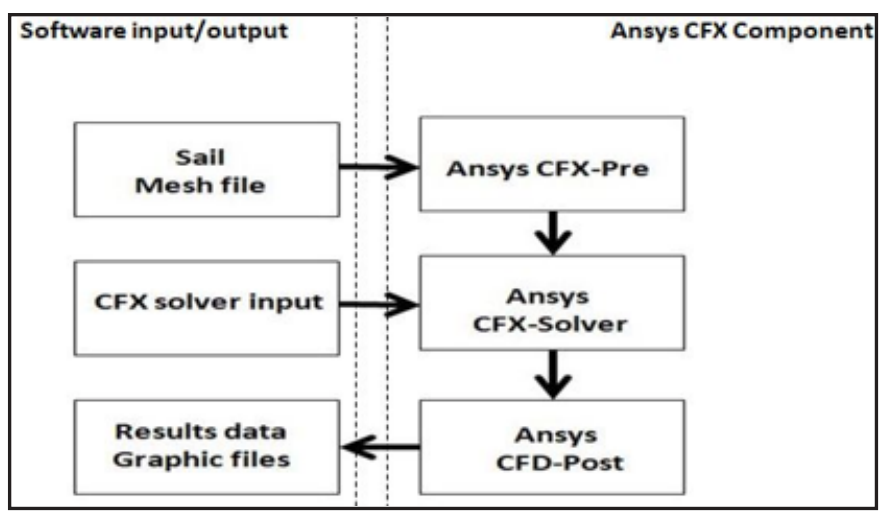

Fig. 4 Schema for CFX components and result data export

CFX can shape the most demanding fluid flow-related dynamics phenomena and solve sophisticated simulations (as presented in commands figure 4) for flows with multiple phases, chemical reaction and combustion. No matter how complicated are the viscous and turbulent, internal and external flows, flow-induced noise predictions, and heat transfer with and without radiation, all these can be easily shaped. CFX in the Workbench refers to CFX running as a component inside of the ANSYS Workbench software.

Inside CFX-pre control panel (figure 5), we used the following boundary conditions for sail simulation:

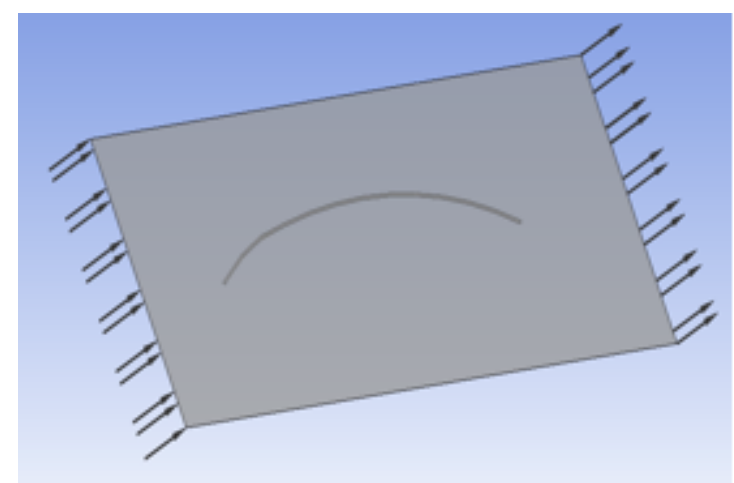

Fig. 5 Sail CFX-pre settings 
- the sail is attacked with a velocity of $10 \mathrm{~m} / \mathrm{s}$, under different angles: $\varphi$ and $\theta$,

- the air density is considered constant and it is equal to $1.225 \mathrm{~kg} / \mathrm{m}^{3}$.

- the atmospheric pressure behind the sail is equal to $101,325 \mathrm{~Pa}$,

- air cinematic viscosity: $0.0001460735 \mathrm{~m}^{2} / \mathrm{s}$

All data are according airflow and air properties described in default solver of CFX and similar to Constana harbour air physical values. To describe Constana area we will use as input data a small speed wind of $2 \mathrm{~m} / \mathrm{s}$ and the turbulence intensity will be $10 \%$ constant during simulation steps.

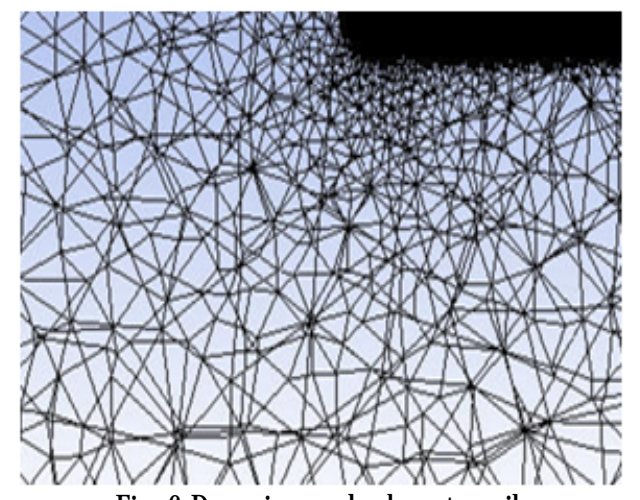

Fig. 6 Domain mesh close to sail

The sail simulation's results (mesh with relevance 100 $\%$ for accurate results- figure 6 ) for drag force and lateral force are presented in table 1, 2, 3, 4 and 5.

Table 1

DRAG, LIFT AND SIDE FORCE FOr $\varphi=0^{\circ}$

\begin{tabular}{|c|c|c|}
\hline $\begin{array}{c}\text { Incidence } \\
\text { Angle } \\
\theta \\
{\left[{ }^{0}\right]}\end{array}$ & $\begin{array}{c}\text { Drag force } \\
D \\
{[\mathrm{~N}]}\end{array}$ & $\begin{array}{c}\text { Side force } \\
\qquad S \\
{[\mathrm{~N}]}\end{array}$ \\
\hline $0^{\circ}$ & 6223.386 & 184.671 \\
\hline $2^{0}$ & 6183.96 & 128.553 \\
\hline $5^{\circ}$ & 5922.591 & 100.893 \\
\hline $10^{\circ}$ & 5838.795 & 43.92 \\
\hline
\end{tabular}

Table 2

DRAG, LIFT AND SIDE FORCE FOR $\varphi=5^{0}$

\begin{tabular}{|c|c|c|}
\hline $\begin{array}{c}\text { Incidence } \\
\text { Angle } \\
\theta\end{array}$ & $\begin{array}{c}\text { Drag force } \\
\boldsymbol{D}\end{array}$ & $\begin{array}{c}\text { Side force } \\
\boldsymbol{C}\end{array}$ \\
{$\left[{ }^{0}\right]$} & {$[\mathbf{N}]$} & {$[\mathbf{N}]$} \\
\hline $0^{0}$ & 6199.581 & 4097.409 \\
\hline $2^{0}$ & 6098.199 & 3930.537 \\
\hline $5^{0}$ & 5751.609 & 3382.482 \\
\hline $10^{\circ}$ & 5542.959 & 2994.137 \\
\hline
\end{tabular}

Table 3

DRAG, LIFT AND SIDE FORCE FOR $\varphi=10^{\circ}$

\begin{tabular}{|c|c|c|}
\hline $\begin{array}{c}\text { Incidence } \\
\text { Angle }\end{array}$ & $\begin{array}{c}\text { Drag force } \\
D\end{array}$ & $\begin{array}{c}\text { Side force } \\
S\end{array}$ \\
\hline $\begin{array}{c}\theta \\
{\left[{ }^{0}\right]}\end{array}$ & {$[\mathrm{N}]$} & \\
\hline $0^{\circ}$ & 5928.24 & 4615.383 \\
\hline $2^{0}$ & 5102.469 & 4010.289 \\
\hline $5^{0}$ & 4890.909 & 3694.527 \\
\hline $10^{\circ}$ & 4799.226 & 3587.889 \\
\hline
\end{tabular}

DRAG, LIFT AND SIDE FORCE FOR $\varphi=15^{\circ}$

\begin{tabular}{|c|c|c|}
\hline $\begin{array}{c}\text { Incidence } \\
\text { Angle } \\
\theta\end{array}$ & $\begin{array}{c}\text { Drag force } \\
\boldsymbol{D}\end{array}$ & $\begin{array}{c}\text { Side force } \\
\text { [ }\end{array}$ \\
\hline $0^{\circ}$ & {$[\mathrm{N}]$} & {$[\mathrm{N}]$} \\
\hline $2^{0}$ & 5134.47 & 4503.21 \\
\hline $5^{0}$ & 4571.991 & 4157.013 \\
\hline $10^{\circ}$ & 4388.457 & 3850.545 \\
\hline
\end{tabular}

Table 5

DRAG, LIFT AND SIDE FORCE FOR $\varphi=20^{\circ}$

\begin{tabular}{|c|c|c|}
\hline $\begin{array}{c}\text { Incidence } \\
\text { Angle }\end{array}$ & $\begin{array}{c}\text { Drag force } \\
\boldsymbol{D}\end{array}$ & $\begin{array}{c}\text { Side force } \\
\boldsymbol{S}\end{array}$ \\
$\begin{array}{c}{\left[^{0}\right]} \\
0^{\circ}\end{array}$ & {$[\mathrm{N}]$} & {$[\mathrm{N}]$} \\
\hline $2^{0}$ & 1763.211 & 890.991 \\
\hline $5^{\circ}$ & 1743.411 & 880.221 \\
\hline $10^{\circ}$ & 1735.422 & 861.867 \\
\hline \multicolumn{3}{|c}{} \\
\hline
\end{tabular}

For specially design sail ships, the time percentage of travel is minimum $50 \%$ of the trip with engine off. The wind is very unpredictable though and you may end spending more for unforeseen reason in some cases you can make more than $75 \%$ trip with engine on. In a numerical prediction of use according to safety features and restrictions, for the rigid sail an increase in performance is estimated by $10 \%$ compared to the classic sail. Considered forces in numerical simulation and wisely dimensions for every ship can have a huge impact on propulsion with rigid sails.

\section{Results and discussions}

CFD post has calculators included and offers results in drag force in each presented simulation case for sail in the hypothesis that the sail is rigid. The most significant force among is the drag force because it is converted into tow force. As presented below higher attack angles of 15 and 20 have a lower drag force.

Visualizing the results for drag and lateral forces is performed using the Postprocessor. The CFX-post is also used for the velocity's distribution in a plane that intersects the sail which includes anything from obtaining point values to complex animated sequences for velocity values (figure 7). Values presented with red colour show a high speed corresponding to low pressure according to Bernoulli law.

The postprocessor CFX-POST is the component used to visualize pressure, speeds and eddy results interactively. Post-processing includes visualization of the geometry and control volumes around the sail and quantitative numerical calculations for specified surfaces and functions defined.

In figure 8 , it is represented the pressure distribution in sail modelling which presents the few spots with domain interaction that will interfere with variable curvature rigid sail CFX simulation. To avoid interaction with requested simulation results, the fluid domain should be dimensioned according to the simulation's needs.

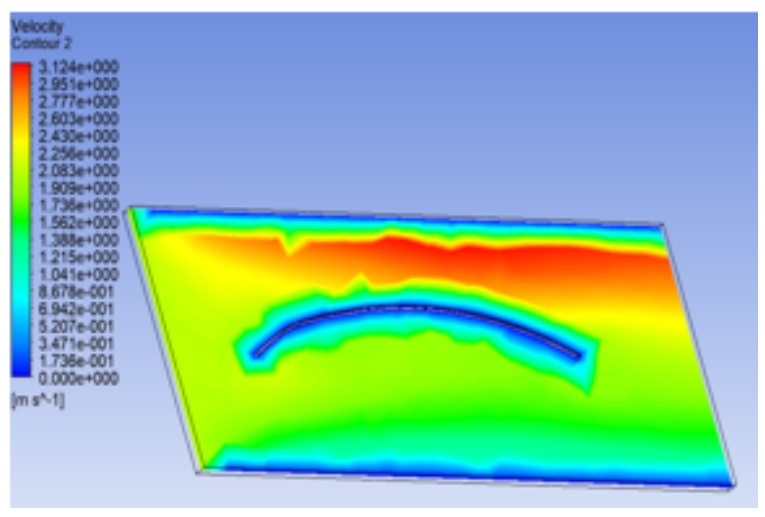

Fig. 7 Velocity distribution 


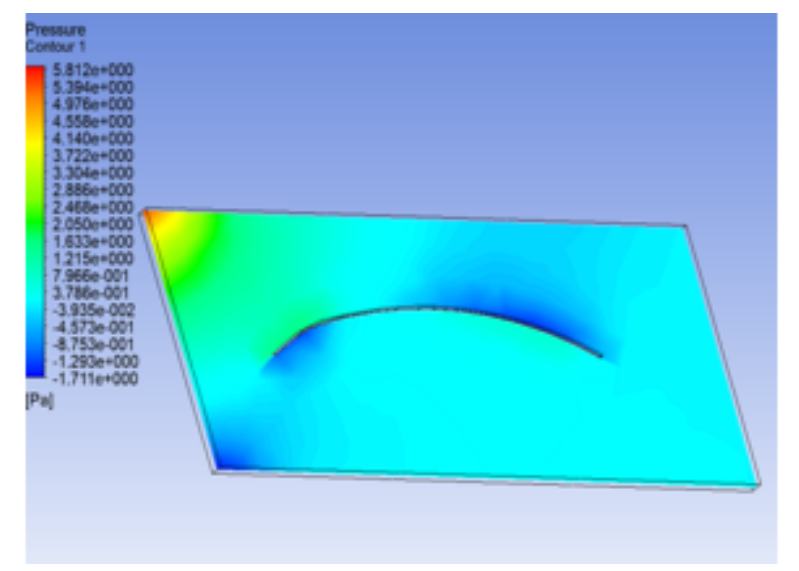

Fig. 8 Velocity distribution

\section{Conclusions}

The present study assesses the application of HPC/CFD numerical simulation for unconventional propulsion. Using rigid sails is usually accompanied by a decrease of tow force and fossil fuel consumption. The HPC/CFD analysis should be carried out for each type of ship to ensure maximum efficiency. The CFD results data for each angle of attack were used to investigate a towing force for the CirusPlast existing fibreglass project Lupo90 in Constanta harbour conditions.

The presented model has high capacity of towing and it can be installed on-board existing ships. The HPC (high performance computing) and CFD (computational fluid dynamics) which is a mixture of actual hardware and software at high level computing power was applied to Lupo90 boat in Constanta harbour conditions. The CFD force estimation method is a real tool in hands of engineers, results can maximize rigid sails use for any requested application.

Acknowledgement: This work was supported by the Romanian Ministry of Defence, PSCD grant 152/2018 and implemented by SC CirusPlast SRL.

\section{References}

1.DUMITRU D., Numerical investigation of a two - Degrees - of Freedom ship model for pitch - Roll motion (2016) IOP Conference Series: Materials Science and Engineering, 145 (8), art. no. 082007, DOI: $10.1088 / 1757-899 X / 145 / 8 / 082007$
2.GLAUERT H., The Elements of Aerofoil and Airscrew Theory, Cambridge Science Classic Series, Cambridge University Press, 2nd edition, 1993.

3.WILSON R. E. and LISSAMAN P. B. S., Applied aerodynamics of wind power machines, PB238595, ReportNSF-RA-N-74-113, NTIS, Springfield, Va, USA, 1974.

4.GLAUERT H., Airplane propellers, in Aerodynamic Theory, vol. 4, Dover, 1963.

5.MARUSIC, G., SANDU, I., FILOTE, C., SEVCENCO, N., CRETU, M. A. Modeling of Spacio - temporal Evolution of Fluoride Dispersion in River-type Systems, Rev. Chim. (Bucharest), 66, no. 4, 2015, p. 503506

6.SABAU A., Comparison of two thermodynamic combustion models, (2018) IOP Conference Series: Earth and Environmental Science, 172 (1), art. no. 112033, DOI: 10.1088/1755-1315/172/1/012033

7.PANAITESCU, V., PAVEL, D., CHISACOF, A., LAZAROIU, G., Free Jet Mist Water Use for Fire Heat Absorption, Rev. Chim. (Bucharest), 63, no.3, 2012, p. 310-315

8.RAICU A., OANTA E, SABAU A., Making objective decisions in mechanical engineering problems(2017) IOP Conference Series: Materials Science and Engineering, 227 (1), art. no. 012108, DOI: 10.1088/1757-899X/227/1/012108

9.STAN L. C., Simulation of air pollution due to marine engines, (2017) IOP Conference Series: Materials Science and Engineering, 227 (1), art. no. 012121, DOI: 10.1088/1757-899X/227/1/012121

10.STAN L. C., CALIMNESCU I., VELCEA D. D., Design check of an SLay offshore pipeline launching using numerical methods, 2016, IOP Conference Series: Materials Science and Engineering, 145 (8), art. no. 082017, DOI: 10.1088/1757-899X/145/8/082017

11.STAN L. C, Computer fluid dynamics (CFD) study of a plate heat exchanger working with nanofluids (2016) Proceedings of SPIE - The International Society for Optical Engineering, 10010, art. no. 1001021, DOI: $10.1117 / 12.2241677$

12.PREDA A., SCUPI A. A., Energy review on a maritime energy transfer system for commercial use (2014) Advanced Materials Research, 837, pp. 763-768. DOI: 10.4028/www.scientific.net/AMR.837.763

13.SCUPI A. A., The use of numerical programs in research and academic institutions (2016) IOP Conference Series: Materials Science and Engineering, 145 (8), art. no. 082002, DOI: 10.1088/1757-899X/145/ $8 / 082002$

$\overline{\text { Manuscript received: } 10.10 .2018}$ 